\title{
Role of Matrix Metalloproteinases in Delayed Neuronal Damage after Transient Global Cerebral Ischemia
}

\author{
Seong-Ryong Lee, Kiyoshi Tsuji, Sun-Ryung Lee, and Eng H. Lo \\ Neuroprotection Research Laboratory, Departments of Neurology and Radiology, Massachusetts General Hospital, Charlestown, Massachusetts 02129, and \\ Program in Neuroscience, Harvard Medical School, Boston, Massachusetts 02114
}

\begin{abstract}
Mechanisms of selective neuronal death in the hippocampus after global cerebral ischemia remain to be clarified. Here, we explored a possible role for matrix metalloproteinases (MMPs) in this phenomenon. Although many studies have demonstrated detrimental roles for the gelatinase MMP-9 in focal cerebral ischemia, how dysregulated MMP proteolysis influences global cerebral ischemia is less well understood. In this study, CD-1 mice were subjected to transient global ischemia. Transient occlusions of common carotid arteries for periods between 20 and $40 \mathrm{~min}$ led to increasing hippocampal neuronal death after $3 \mathrm{~d}$. Gel zymography showed elevations in gelatinase (MMP-2 and MMP-9) activity. In situ zymography showed that gelatinase activity was mostly colocalized with neuron-specific nuclear protein-stained pyramidal neurons. Mice treated with the broad-spectrum metalloproteinase inhibitor BB-94 (50 mg/kg, i.p.) showed reduced hippocampal gelatinase activity after transient global cerebral ischemia and suffered significantly reduced hippocampal neuronal damage compared with vehicle-treated controls $(p<0.01)$. Additionally, hippocampal gelatinase activity and neuronal damage after transient global ischemia were also significantly reduced in MMP-9 knock-out mice compared with wild-type mice $(p<0.05)$. These data indicate a potential deleterious role for MMP-9 in the pathogenesis of delayed neuronal damage in the hippocampus after global cerebral ischemia.
\end{abstract}

Key words: stroke; neuroprotection; hippocampus; mouse; neuroinflammation; MMPs

\section{Introduction}

Transient global cerebral ischemia results in an intriguing profile of selective neuronal injury. Cell death is delayed for 3-5 d after ischemia, and despite a uniform insult, neuronal demise is typically restricted to selected parts of the hippocampus, subsets of striatal neurons, and specific layers of the cortical lamina. Although this selective vulnerability to ischemia has been recognized for a long time (Pulsinelli, 1985), the molecular mechanisms that underlie this neurobiological mystery remain to be fully resolved. Various manifestations of fundamental neuron death pathways have been invoked to explain this phenomenon, including excitotoxicity, free radical stress, and apoptotic-like mechanisms (Bondy, 1995; Lipton, 1999; Chan, 2001; Graham and Chen, 2001; Lo et al., 2003).

In addition to the primarily intracellular pathways outlined above, emerging data suggest that extracellular pathophysiology may also influence cerebral ischemic outcomes. One of the first pieces of evidence supporting this idea was the finding that mice deficient in tissue plasminogen activator were protected against

Received Sept. 17, 2003; revised Nov. 4, 2003; accepted Nov. 4, 2003.

This work was supported in part by National Institutes of Health Grants R01-NS37074, R01-NS38731, R01NS40529, and P50-NS10828. We thank Xiaoying Wang for many helpful discussions.

Correspondence should be addressed to Eng H. Lo, Neuroprotection Research Laboratory, MGH East 149-2401, Charlestown, MA 02129. E-mail: Lo@helix.mgh.harvard.edu.

DOI:10.1523/JNEUROSCI.4243-03.2004

Copyright $\odot 2004$ Society for Neuroscience $\quad$ 0270-6474/04/240671-08\$15.00/0 hippocampal injury after kainic acid injections (Tsirka et al., 1996). This protection was linked to decreased laminin degradation (Chen and Strickland, 1997), suggesting that loss of cellmatrix homeostasis may mediate selective neuronal death. More recently, it has been shown that another class of extracellular proteases, the matrix metalloproteinases (MMPs), may also degrade extracellular matrix and trigger anoikis-like cell death in neurons (Gu et al., 2002). MMPs comprise an important family of proteases associated with basement membrane and extracellular matrix remodeling and are involved in both physiological and pathological CNS processes (Pagenstecher et al., 1998; Yong et al., 1998). In particular, the gelatinases (MMP-2 and MMP-9) have been implicated specifically in cerebral ischemia (Lo et al., 2002). Knock-out (KO) mice deficient in MMP-9 are protected against brain trauma and focal cerebral ischemia (Wang et al., 2000; Asahi et al., 2001b). The mechanisms of injury may involve MMP-9-mediated disruption of blood-brain barrier integrity, edema, and hemorrhagic conversion, as well as white matter myelin degradation.

Recently, it has been suggested that MMPs may be upregulated in hippocampus after global brain ischemia (Rivera et al., 2002; Zalewska et al., 2002). In the present study, we examine more closely this involvement of MMPs using a combination of pharmacologic and genetic approaches. We show that inhibition with a broad-spectrum metalloproteinase inhibitor ameliorates dysregulated gelatinase activity and reduces hippocampal neuronal death after transient global cerebral ischemia in mice. Furthermore, MMP-9 knock-outs are also protected, consistent with a specific role for this protease. 


\section{Materials and Methods}

Ischemia protocol. All experiments were performed following an institutionally approved protocol in accordance with The National Institutes of Health Guide for the Care and Use of Laboratory Animals. In experiments to document the ischemic upregulation of MMP-9, normal male CD-1 mice were used. For all other experiments, male MMP-9 KO mice and their corresponding wild-type littermates were used; these were bred from a CD-1 background (Vu et al., 1998). General anesthesia was maintained with $1-1.5 \%$ halothane via facemask. Laser-Doppler flowmetry was used to measure cerebral cortical microperfusion $(3 \mathrm{~mm}$ lateral to bregma). Body temperature was monitored and maintained at 36.5$37.5^{\circ} \mathrm{C}$ with a feed-back heating pad. Both common carotid arteries were carefully isolated from the adjacent vagus nerve and occluded for $40 \mathrm{~min}$ with micro-clips. To reperfuse, clips were removed and patency of arteries was confirmed by inspection. In our experimental model, only mice that showed $<20 \%$ of baseline control microperfusion during the first minute of occlusion were used in subsequent experiments. To determine the optimal duration of bilateral common carotid occlusion, a study using CD-1 mice was performed to evaluate neuronal cell damage after 20,30 , and $40 \mathrm{~min}$ of occlusion ( $n=6$, respectively). BB-94 (British Biotech, Oxford, UK) was used as a broad-spectrum metalloproteinase inhibitor. $\mathrm{IC}_{50}$ values for enzyme inhibition of representative MMP are as follows: $5 \mathrm{nmol} / \mathrm{l}$ for MMP-1, $4 \mathrm{nmol} / \mathrm{l}$ for MMP-2, $20 \mathrm{mmol} / \mathrm{l}$ for MMP-3, $6 \mathrm{nmol} / 1$ for MMP-7, and $3 \mathrm{nmol} / 1$ for MMP-9 (Batimastat technical information sheet; British Biotech). In all studies, BB-94 was administered intraperitoneally as a suspension of $3 \mathrm{mg} / \mathrm{ml}$ in $\mathrm{PBS}, \mathrm{pH}$ 7.2 , containing $0.01 \%$ Tween 80 . The intraperitoneal route has led effective delivery of inhibitor to brain (Paez Pereda et al., 2000). Mice were treated twice at $30 \mathrm{~min}$ before and $3 \mathrm{hr}$ after start of transient global ischemia $(50 \mathrm{mg} / \mathrm{kg}$ per dose), which was followed by additional treatments once a day on the second and third day. Controls received PBS containing $0.01 \%$ Tween 80 .

Analysis of hippocampal injury. For evaluation of histological damage, brain slices were stained with $0.1 \%$ cresyl violet according to the Nissl method. Viable neurons were defined as neurons in which a clear nucleus could be seen. With Nissl staining, ischemic damaged neurons exhibit features including pyknosis and shrunken cell bodies. Hippocampal neuronal damage was evaluated qualitatively according to the method of Kawase et al. (1999): grade 0, no damage to any hippocampal subregion; grade 1, scattered ischemic neurons in CA1 subregion; grade 2, moderate ischemic damage in CA1 subregion (less than half of pyramidal cells affected); grade 3 , severe damage to pyramidal cells in CA1 subregion (more than half of pyramidal cells affected); grade 4, extensive cell damage in all hippocampal subregions. Neuronal damage was evaluated by a researcher (K.T.) blinded to the studies.

Preparation of tissue extracts. At 6, 24, or $72 \mathrm{hr}$ after ischemic onset, mice were anesthetized deeply and then perfused transcardially with icecold PBS, pH 7.4. The brains were removed quickly, and hippocampus was dissected, frozen immediately on dry ice, and stored at $-80^{\circ} \mathrm{C}$. Brain tissue extracts were prepared as described previously (Asahi et al., 2001b). Briefly, brain samples were homogenized in lysis buffer including protease inhibitors on ice. After centrifugation, supernatant was collected, and total protein concentrations were determined using the Bradford assay (Bio-Rad, Hercules, CA).

Gel zymography. Prepared protein samples were loaded and separated by $10 \%$ Tris-glycine gel with $0.1 \%$ gelatin as substrate. After separation by electrophoresis, the gel was renaturated and then incubated with developing buffer at $37^{\circ} \mathrm{C}$ for $24 \mathrm{hr}$ as described previously (Asahi et al., 2001b). After developing, the gel was stained with $0.5 \%$ Coomassie Blue R-250 for $30 \mathrm{~min}$ and then destained appropriately.

In situ zymography. In situ zymography was issued to detect and localize enzyme activity in tissue sections (Oh et al., 1999). After transcardial perfusion with ice-cold PBS, pH 7.4, brains were quickly removed without fixation and frozen in 2-methylbutane with liquid nitrogen. Sections $(20 \mu \mathrm{m})$ were cut on a cryostat and incubated at room temperature overnight in $0.05 \mathrm{M}$ Tris- $\mathrm{HCl}, 0.15 \mathrm{M} \mathrm{NaCl}, 5 \mathrm{~mm} \mathrm{CaCl}_{2}$, and $0.2 \mathrm{~mm}$ $\mathrm{NaN}_{3}, \mathrm{pH} 7.6$, containing $40 \mu \mathrm{g}$ of FITC-labeled gelatin (Molecular Probes, Eugene, OR). The gelatin with a fluorescent tag remains caged (no fluorescence) until the gelatin is cleaved by gelatinase activity. This method detects regionally specific gelatinolytic activity but does not distinguish between MMP-9 and MMP-2. In each experiment, some sections contained metalloproteinase inhibitors in the reaction buffer $(200$ $\mu \mathrm{M}$ of GM-6001 or $1 \mathrm{mM}$ of 1,10-phenanthroline). The in situ gelatinolysis was revealed by the appearance of fluorescent brain constituents. Neurons were identified by immunofluorescence staining of neuronspecific nuclear protein (NeuN). Sections were incubated with antiNeuN monoclonal antibody (1:100; Chemicon, Temecula, CA) and the secondary antibody [anti-mouse tetramethylrhodamine isothiocyanate (TRITC), 1:100; Jackson ImmunoResearch, West Grove, PA]. Astrocytes were stained with anti-glial fibrillary acidic protein (GFAP) antibody (1:200; Chemicon) and the secondary antibody (anti-mouse TRITC, 1:100; Jackson ImmunoResearch). Reaction products were visualized by fluorescence microscope.

Immunohistochemistry for MMP-9. Double-label immunohistochemistry was performed. To assess the distribution of MMP-9 after transient global ischemia, anesthetized animals were perfused transcardially with ice-cold PBS, pH 7.4, followed with ice-cold $4 \%$ paraformaldehyde in $\mathrm{PBS}, \mathrm{pH}$ 7.4. The brains were removed, immersed with the same fixative overnight at $4^{\circ} \mathrm{C}$, and cryoprotected in 15 and $30 \%$ sucrose solutions in $\mathrm{PBS}$ at $4^{\circ} \mathrm{C}$. Frozen coronal sections $(20 \mu \mathrm{m}$ thick) were prepared using a cryostat. After blocking with PBS containing $0.2 \%$ Triton X-100 and 3\% normal goat serum, sections were incubated overnight at $4^{\circ} \mathrm{C}$ with the MMP-9 rabbit polyclonal antibody (1:200; a kind gift from Dr. Robert Senior, Washington University, St. Louis, MO) in combination with anti-NeuN monoclonal antibody (1:100; Chemicon) or anti-GFAP antibody (1:200; Chemicon) in PBS $0.2 \%$ Triton X-100 and 2\% normal goat serum. The sections were washed with PBS, incubated with secondary antibody solutions (anti-rabbit FITC, 1:200, and anti-mouse TRITC, 1:100; Jackson ImmunoResearch) for $30 \mathrm{~min}$. Negative control sections received identical treatment except for the primary antibodies of double staining.

Statistical analysis. Data were expressed as mean $\pm \mathrm{SD}$, and statistical analysis was performed by the Student's $t$ test (for comparisons between two groups) and an ANOVA followed by Bonferroni post hoc test (for comparisons among multiple groups). Significance refers to results for which $p<0.05$ was obtained.

\section{Results \\ Hippocampal neuronal injury after transient global cerebral ischemia}

To determine the optimal duration of bilateral common carotid occlusion for our model, CD-1 mice were subjected to 20,30 , or $40 \mathrm{~min}$ of ischemia. Animals were killed $72 \mathrm{hr}$ after ischemia. Increasing durations of ischemia resulted in correspondingly increased neuronal damage in the hippocampus (Fig. $1 A, B$ ). In this model, 40 min of transient occlusions resulted in reproducible and statistically significant injury $(p<0.001)$ compared with sham-operated animals, and damage was restricted mainly to neurons in the pyramidal layer (Fig. $1 B, C$ ). This was the ischemic duration selected for the rest of our experiments.

\section{Increased MMP-9 and MMP-2 after transient global ischemia} Protein levels of MMP-9 and MMP-2 in mouse hippocampus were evaluated using gelatin zymography. In nonischemic shamoperated brains, $72 \mathrm{kDa}$ forms of MMP-2 were present, but within the limits of our sensitivity, no detectable levels of MMP-9 were observed (Fig. 2A). After transient global cerebral ischemia, $72 \mathrm{kDa}$ MMP-2 and $97 \mathrm{kDa}$ MMP-9 in hippocampus were increased over time. Compared with nonischemic baselines, elevations in MMP-9 became statistically significant by $6 \mathrm{hr}$ after ischemia (Fig. 2 B). In contrast, significant elevations in MMP-2 were delayed until $72 \mathrm{hr}$ after ischemia (Fig. 2C).

To assess the anatomic distribution of MMP activity, in situ gelatin zymography was performed at $3 \mathrm{~d}$ after ischemia. In- 

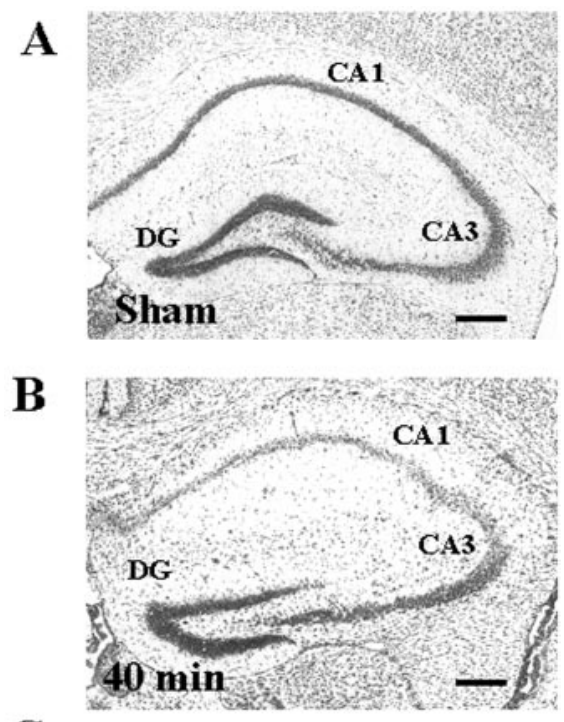

C

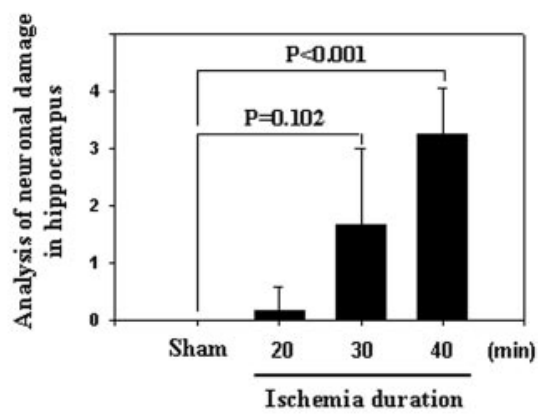

Figure 1. Photomicrographs of Nissl staining in hippocampus after transient global cerebral ischemia. $A$, Sham-operated brain shows clear delineation of pyramidal layer and dentate gyrus. $B$, Three days after 40 min transient cerebral ischemia, pyramidal neurons are severely damaged. $C$, Increasing hippocampal damage (mean + SD score) after increasing duration of transient cerebral ischemia; Sham $(n=3)$; all other groups ( $n=6$ per group). Scale bars, $300 \mu \mathrm{m}$. DG, Dentate gyrus; CA1, cornus ammonis sector 1; CA3, cornus ammonis sector 3 .

creased gelatinase activity was clearly observed in the hippocampus, primarily within the pyramidal and granular layers (Fig. $3 A-C)$. To confirm that the proteolytic activity is attributable to MMPs, sections were coincubated with the general metalloproteinase inhibitor GM6001. In all cases, GM6001 clearly reduced the gelatinase activity in postischemic hippocampus (Fig. 3D-F). Additionally, another metalloproteinase inhibitor, 1,10phenanthroline, also reduced postischemic gelatinase activity (data not shown).

To determine the cellular sources involved, sequential immunohistochemistry was performed on sections immediately after in situ zymography was completed. NeuN staining showed that gelatinase activity was located mainly in pyramidal and granular neurons (Fig. 4). Nevertheless, in regions adjacent to these pyramidal and granular layers, some association of gelatinase activity with GFAP staining was also observed, suggesting that astrocytes may contribute to this response (data not shown). Finally, in situ zymography also demonstrated vascular-like signals in postischemic hippocampus, suggesting some degree of endothelial expression (data not shown).

Because in situ zymography cannot distinguish between MMP-2 and MMP-9, immunohistochemistry was performed. There were very low levels of MMP-9 expression in shamoperated control brains (data not shown). After transient global
A

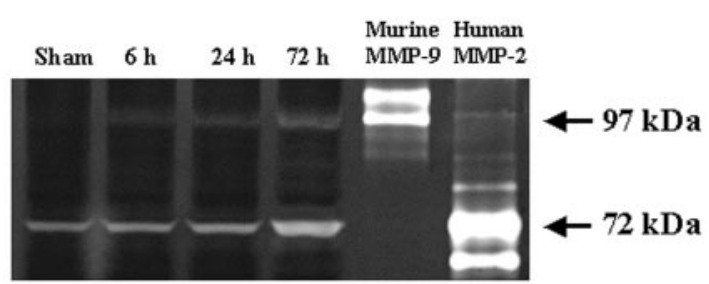

B
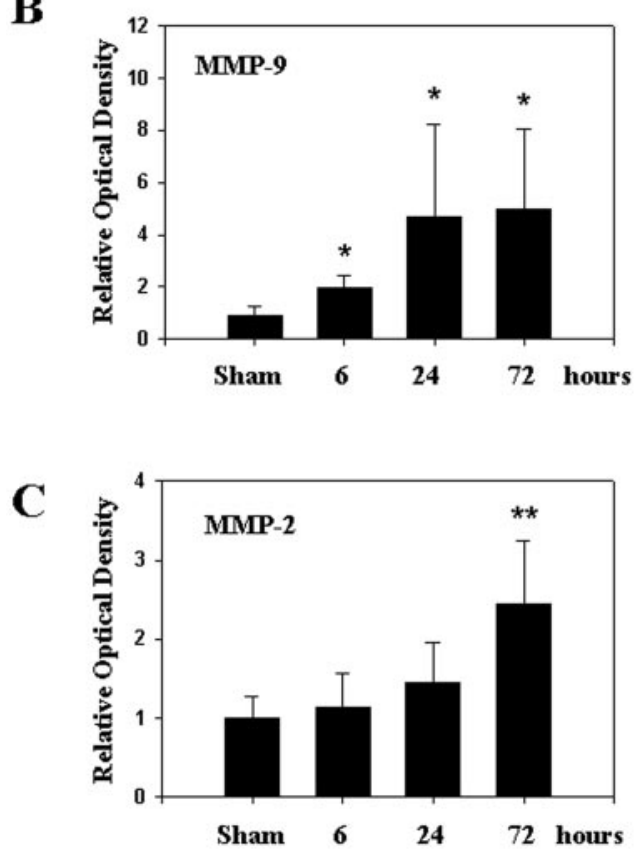

Figure 2. Gel zymography of hippocampal brain homogenates after $40 \mathrm{~min}$ transient cerebral ischemia. $A$, Representative zymogram gel showing elevation of MMP-9 and MMP-2. Murine MMP-9 and human MMP-2 were loaded as standards. B, Quantitative increases in relative optical density for active $97 \mathrm{kDa}$ MMP-9 (mean $+S D ; n=6$ ). C, Quantitative increases in relative optical density for $72 \mathrm{kDa}$ proforms of MMP-2 (mean $+\mathrm{SD} ; n=6$ ). ${ }^{*} p<0.05$; ${ }^{* *} p<0.01$.

ischemia, an increase of MMP-9 was observed in hippocampus, occurring predominantly in pyramidal and granular layers with neuronal and glial-like morphology. NeuN staining showed that MMP-9 expression was located mainly in pyramidal (Fig. $5 A-D$ ) and granular neurons (Fig. 5E-H). Interestingly, MMP-9 immunoreactivity tended to show a diffuse pattern, suggesting some extracellular localization as well. GFAP staining showed that MMP-9 expression was also located in astrocytes within both pyramidal (Fig. 6A-D) and granular layers (Fig. $6 E-H$ ). No detection was observed in negative controls in which postischemic brain sections were incubated without the primary antibodies (Figs. 5G,H, 6G,H).

\section{Hippocampal protection by MMP inhibition}

To pharmacologically assess the pathologic role for MMPs in our model of transient global cerebral ischemia, we used the broadspectrum metalloproteinase inhibitor BB-94. Mice treated with BB-94 showed decreased gelatinase activity on in situ zymography at $3 \mathrm{~d}$ after ischemia compared with vehicle-treated controls (Fig. 7A). Correspondingly, hippocampal neuronal damage was also significantly reduced by MMP inhibition (Fig. $7 B, C)(p<$ $0.01)$. 


\section{Vehicle}
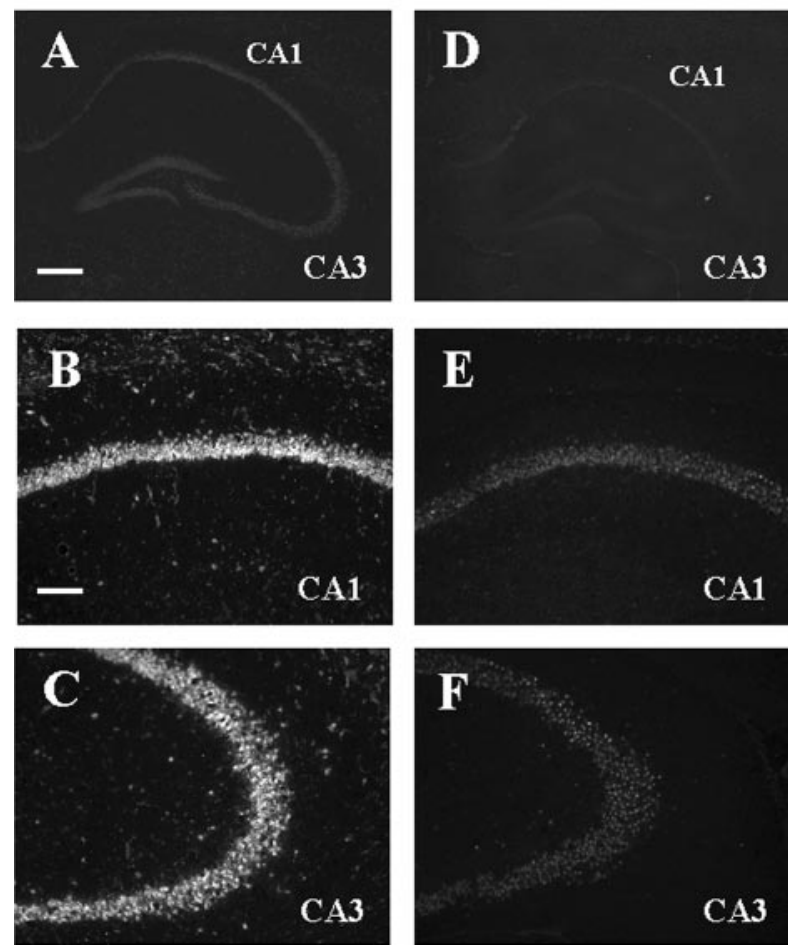

Figure 3. A-C, Representative in situ gelatin zymograms in hippocampus at $3 \mathrm{~d}$ after $40 \mathrm{~min}$ transient global cerebral ischemia. $D-F$, Suppression of gelatinolytic activity in postischemic hippocampus after coincubation with the metalloproteinase inhibitor GM6001. Scale bars: $A$, $300 \mu \mathrm{m} ; B, 100 \mu \mathrm{m}$.

\section{CA1}
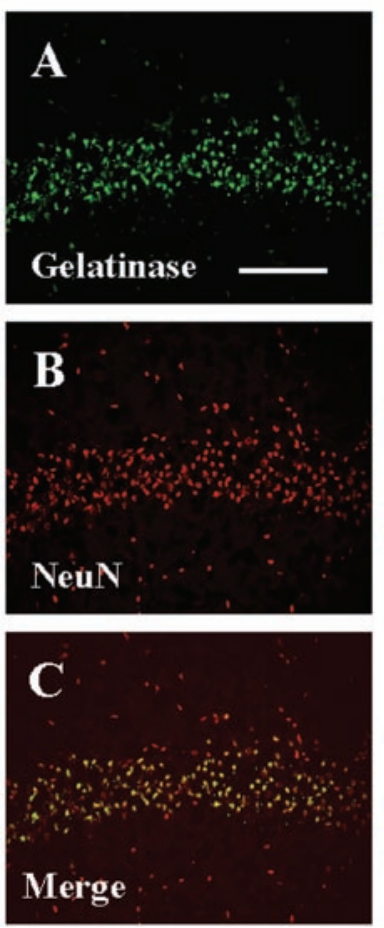

\section{Dentate Gyrus}
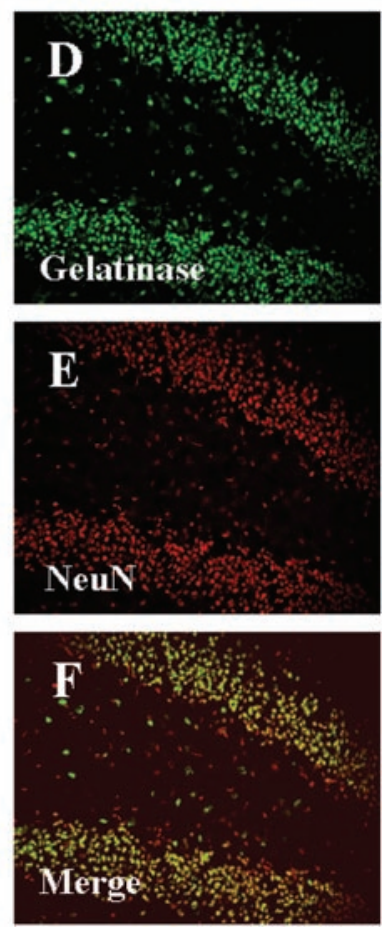

Figure 4. Cellular localizations of gelatinolytic activity in postischemic hippocampus (3 d after 40 min transient global cerebral ischemia). Increased gelatinolytic activity (green fluorescence) broadly colocalizes with NeuN staining of neurons (red fluorescence). A-C, CA1 sector. $D-F$, Dentate gyrus region. Scale bar, $100 \mu \mathrm{m}$.
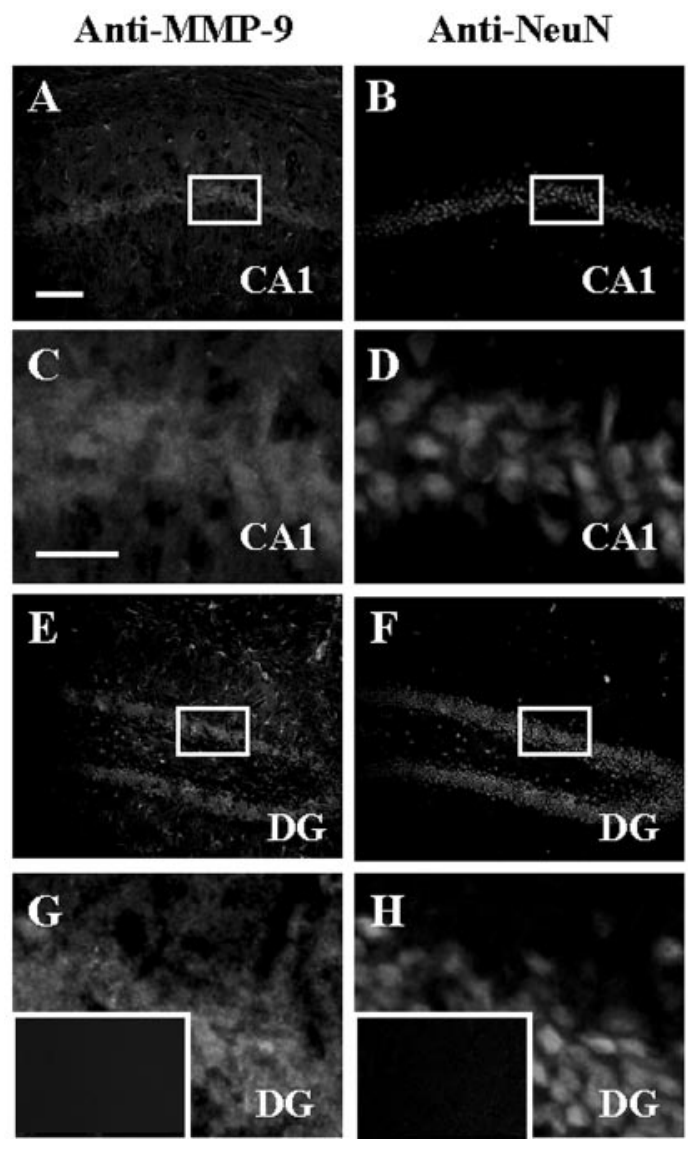

Figure 5. MMP-9 immunohistochemistry (green fluorescence) in postischemic hippocampus shows colocalization with NeuN staining of neurons (red fluorescence). Signals appear to suggest intracellular and extracellular localizations. $A-D$, CA1 sector. $E-H$, Dentate gyrus regions. $G, H$, Insets, Negative controls for immunohistochemistry data (FITC or TRITC secondary antibodies alone without primary antibodies). Scale bars: $A, 100 \mu \mathrm{m} ; C, 33 \mu \mathrm{m}$.

\section{Hippocampal protection in MMP-9 knock-out mice}

To further assess the role for MMPs, we used MMP-9 knock-out mice. In wild-type mice, hippocampal gelatinase activity was elevated at $3 \mathrm{~d}$ after transient global cerebral ischemia, as expected (Fig. 8). Gelatinase activity was markedly reduced in MMP-9 knock-outs (Fig. $8 \mathrm{~A}$ ), suggesting that most of the gelatinase activity in this ischemia model may be attributed to MMP-9 and not MMP-2. Correspondingly, hippocampal neuronal damage was significantly reduced in MMP-9 knock-outs compared with wild-type mice (Fig. $8 B, C)(p<0.05)$.

\section{Discussion}

Selective neuronal death in the hippocampus is a signature outcome of transient global cerebral ischemia. Many mechanisms have been postulated, including excitotoxic, free radical, and apoptotic pathways in vulnerable cells (Endoh et al., 1994; Chen et al., 1996; Choi, 1996; Martin et al., 1998; Kawase et al., 1999). An involvement of excitotoxic glutamate was first suggested on the basis of the discovery that disruption of the entorhinal input prevented hippocampal injury after transient global ischemia (Pulsinelli, 1985; Wieloch et al., 1985). It was demonstrated further that there was a relative reduction in calcium-impermeable GluR2 subunits of the AMPA receptors that may amplify deleterious calcium influx (Pellegrini-Giampietro et al., 1992), in part mediated by upregulation of the gene silencer RE-1 silencing transcription factor (Calderone et al., 2003). Additionally, neu- 
Anti-MMP-9
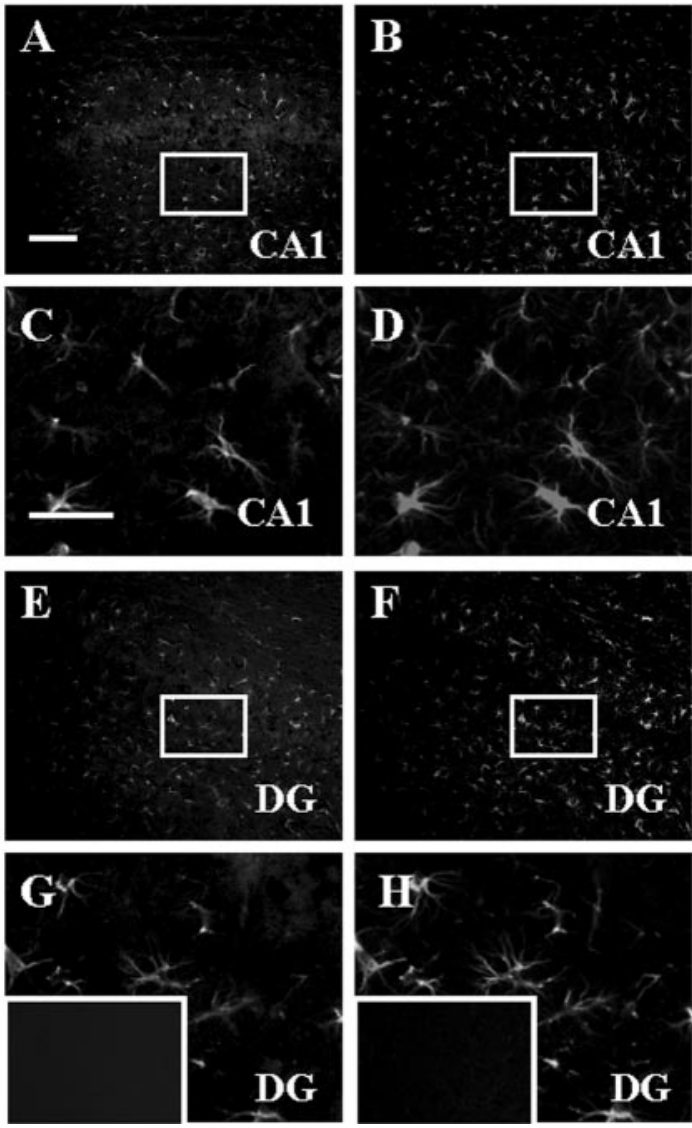

Figure 6. MMP-9 immunohistochemistry (green fluorescence) in postischemic hippocampus shows colocalization with GFAP staining of astrocytes (red fluorescence). $A-D, C A 1$ sector. $E-H$, Dentate gyrus regions. $G, H$, Insets, Negative controls for immunohistochemistry data (FITC or TRITC secondary antibodies alone without primary antibodies). Scale bars: $A, 100 \mu \mathrm{m}$; C, $33 \mu \mathrm{m}$.

rons from the vulnerable CA1 hippocampal sector were more sensitive to oxygen radicals compared with CA3 neurons, consistent with a role for oxidative stress (Wilde et al., 1997). Furthermore, transgenic mice overexpressing superoxide dismutase genes were resistant against cerebral ischemia (Murakami et al., 1997; Chan et al., 1998). Finally, apoptotic-like pathways were implicated because executioner caspase-3 was selectively upregulated in vulnerable hippocampal neurons after transient global cerebral ischemia (Chen et al., 1998). In the present study, we showed that in addition to these primarily intracellular mechanisms, extracellular pathology may also play an important role. Others have suggested that hippocampal injury coincided with dysregulated extracellular proteolysis involving tissue plasminogen activator (Sappino et al., 1993; Tsirka et al., 1996; Chen and Strickland, 1997; Endo et al., 1999) and MMP systems (Zalewska et al., 2002, 2003). Here, our major findings were that (1) MMP-9 was upregulated in hippocampus after transient global cerebral ischemia, (2) suppression of enzyme activity with metalloproteinase inhibitors decreased neuronal death, and (3) MMP-9 knock-out mice had attenuated injury compared with wild-type mice.

A role for MMPs in brain injury after focal ischemia and trauma has been proposed (Rosenberg, 1995, 2002; Mun-Bryce and Rosenberg, 1998; Yong et al., 1998; Rosenberg et al., 2001; Yong et al., 2001; Lo et al., 2002). MMPs, especially MMP-2 and
A
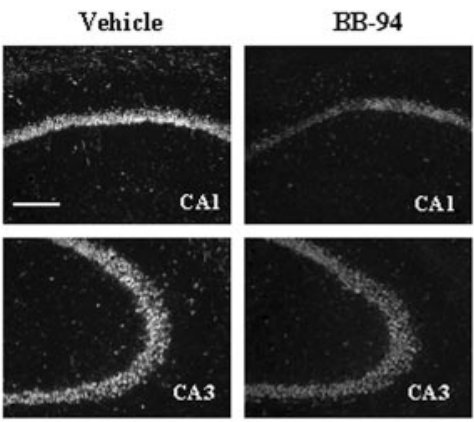

B
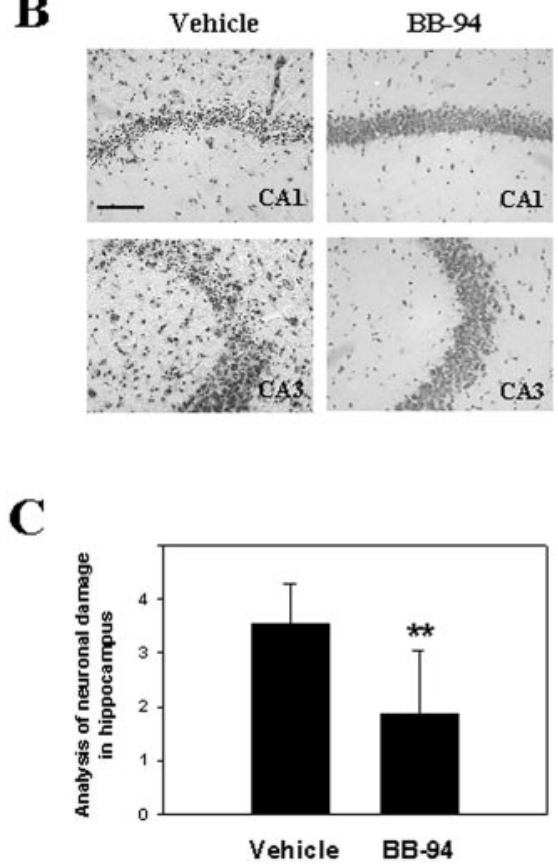

Figure 7. Neuroprotection with pharmacologic MMP inhibition. $A$, Representative sections show that in situ gelatinolytic activity within postischemic hippocampus is reduced in BB-94treated mice compared with vehicle controls at $3 \mathrm{~d}$ after 40 min transient global cerebral ischemia. B, Nissl-stained sections show improved neuronal survival after MMP inhibition. C, Quantified scores (mean + SD) of hippocampal neuronal damage are significantly reduced in BB-94 treated mice $(n=7)$ compared with vehicle controls $(n=10) .{ }^{* *} p<0.01$. Scale bars: $A, 200$ $\mu \mathrm{m} ; B, 100 \mu \mathrm{m}$.

MMP-9, become upregulated, and degradation of neurovascular matrix leads to edema, hemorrhage, and cell death. At least in mouse systems, a dominant role has been ascribed to MMP-9 because MMP-9 knock-out mice were protected against ischemia and trauma (Wang et al., 2000; Asahi et al., 2001b), whereas MMP-2 knock-out mice were not protected (Asahi et al., 2001a). Here, we showed for the first time that MMP-9 may also play a key role in selective neuronal death after global cerebral ischemia. MMP-9 is upregulated in postischemic hippocampus, and MMP-9 gene knock-out ameliorated neuronal demise. In comparing MMP-2 versus MMP-9 in our model, we believe that MMP-9 is the dominant protease because in situ gelatinase activity in postischemic hippocampus was clearly reduced in the MMP-9 knock-outs. Nevertheless, a caveat here is that our limited focus on the gelatinases may miss important roles for other MMPs. MMP-3 is upregulated after neuroinflammation (MunBryce et al., 2002) and under some conditions may ameliorate 
$\mathbf{A}$

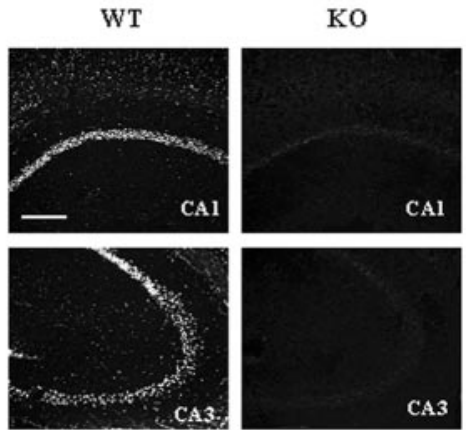

B

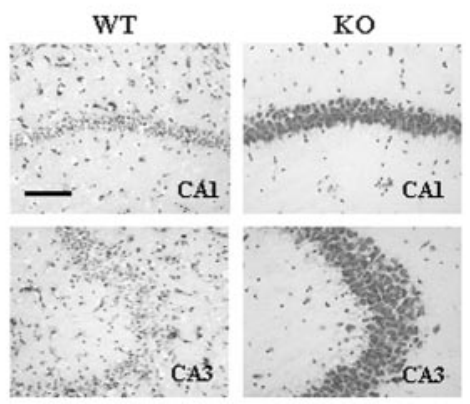

C

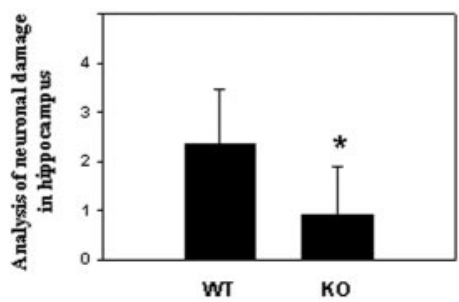

Figure 8. Neuroprotection in MMP-9 knock-out mice. A, Representative sections show that in situ gelatinolytic activity within postischemic hippocampus is reduced in MMP-9 knock-out mice compared with matching wild-types at $3 \mathrm{~d}$ after $40 \mathrm{~min}$ transient global cerebral ischemia. $B$, Nissl-stained sections show improved neuronal survival in MMP-9 knock-outs. C, Quantified score (mean + SD) of hippocampal neuronal damage is significantly reduced in MMP-9 knockout mice $(n=7)$ compared with wild-type controls $(n=5) .{ }^{*} p<0.05$. Scale bars: $A, 200 \mu \mathrm{m}$; $B, 100 \mu \mathrm{m}$.

neuronal apoptosis induced by tissue inhibitor of metalloproteinase-3 (TIMP-3) (Wetzel et al., 2003). In models of intracerebral hemorrhage and experimental allergic encephalomyelitis, MMP-12 is upregulated, and suppression of this protease morphologically protects and improves functional recovery (Power et al., 2003; Yong et al., 2003). Other MMPs besides gelatinases will have to be assessed to determine the overall response of this large protease family in cerebral ischemia.

A central issue in the study of MMPs is whether increased protein levels translate into increased protease activities. Because MMPs can degrade almost all components of the extracellular matrix, activities are tightly regulated at multiple levels. Transcriptional control is mediated by activator protein-1, nuclear factor $\kappa \mathrm{B}$, and other promoter elements of many inducible MMP genes. These transcription factors are known to respond rapidly to cell stress, thus allowing MMPs to participate in cerebral ischemia. Here, we did not measure MMP-9 mRNA, but increased protein levels suggested that upregulation did occur. Furthermore, MMPs are generated as zymogens and cleavage of pro- enzyme is required for protease activity. Our gelatin zymograms of hippocampal homogenates detected cleaved $97 \mathrm{kDa}$ forms of MMP-9, suggesting that active enzyme was present. Only proenzyme forms of MMP-2 were detected but because active enzymes may be unstable during extraction, the actual ratios of pro versus active forms cannot be quantified unequivocally. Finally, MMPs are modulated by an endogenous family of inhibitors known as TIMPs. TIMPs are also increased after focal and global cerebral ischemia (Romanic et al., 1998; Wang et al., 1998; Rivera et al., 2002), so an important question is whether the overall balance between protease (MMP-9) and inhibitor (TIMP1) is changed in our model. Although we did not measure TIMP1 levels here, in situ gelatin zymography may be a reliable indicator of net protease activities. Because clear elevations in gelatinase activity were noted in the postischemic hippocampus, we believe that an imbalance between MMP-9 and endogenous TIMPs occurred. Differential changes in various cell types may also be important. Indeed, our in situ gelatinase assay and MMP-9 immunohistochemistry do not match completely. In part, these differences are likely related to different sensitivities of in situ zymography versus immunohistochemistry. Similar differences between the two techniques have been shown previously for hippocampal remodeling after kainate lesions (Szklarczyk et al., 2002). Overall, however, pyramidal and granular distributions of dysregulated MMP-9 in neurons match up well for both techniques in the present study. Interestingly, the primarily neuronal localization of MMP-9 signals here contrasts with mostly vascular loci after focal ischemia (Asahi et al., 2001b; Wang et al., 2003), pointing to potentially important differences in these different stroke models.

The pathologic role for MMPs in focal brain injury has been attributed primarily to neurovascular matrix degradation, blood-brain barrier disruption, and ultimately hemorrhage, edema, and increased inflammatory influx (Rosenberg, 1995; Mun-Bryce and Rosenberg, 1998; Romanic et al., 1998; Lo et al., 2002). These mechanisms of MMP-mediated damage have been delineated extensively in many models; however, in the case of global cerebral ischemia, neurovascular events are not likely to play a major role. There is no blood-brain barrier leakage in this model, and edema is not an issue. Therefore, the question arises as to how dysregulated MMPs may contribute to hippocampal neuronal injury. One potential mechanism may involve anoikislike cell death that is triggered by loss of cell-matrix interactions. Although anoikis has traditionally been described for epithelial cells (Frisch and Francis, 1994), it is increasingly recognized that similar anoikis-like pathways may operate in neurons as well. Loss of neuron-matrix interactions promote neurotoxicity by downregulating integrin signaling pathways (Gary and Mattson, 2001; Gary et al., 2003). In mouse hippocampus, kainate excitotoxicity is reduced in tissue plasminogen activator (tPA) knockout mice (Tsirka et al., 1997). The model suggests that tPAmediated degradation of homeostatic neuron-laminin matrix interactions serve to amplify hippocampal injury (Tsirka et al., 1997). In addition to the plasminogen system, the other major extracellular protease system in brain comprises the MMPs (Yong et al., 1998, 2001; Lo et al., 2002). MMP-9 degradation of neuronal extracellular matrix promotes cell death $(\mathrm{Gu}$ et al., 2002). Similar mechanisms may be involved in our model. A limitation here is that we did not measure substrate degradation and so cannot truly identify the extracellular mechanisms that mediate MMP-9 neurotoxicity. Reduction of MMP-9 activity by either enzyme inhibition or gene knock-out, however, reduced hippocampal proteolysis and subsequent cell death, thus directly 
implicating a deleterious role for this protease. Importantly, it has been shown recently that tPA can upregulate MMP-9 in brain, thus linking these two protease systems in cerebral ischemia and cell death (Wang et al., 2003).

Neurologic recovery after hippocampal injury is associated with neuroplastic responses over time (Kesslak and Gage, 1986; Schulz et al., 1992; Ramirez, 2001; Nakatomi et al., 2002). After kainate lesions in the hippocampus, MMP-9 upregulation in the dentate gyrus appeared to mediate dendritic remodeling and sprouting (Szklarczyk et al., 2002). In our model, similar events may also occur. Although increased gelatinase activity in the pyramidal cell layers of the hippocampus was associated with neuronal death, increased activity in the dentate gyrus was not. This potential confound may be related to divergent roles for MMPs in brain injury. In the acute phase, deleterious actions may involve neurovascular matrix degradation and possibly anoikis-like neuronal injury, but in the recovery phase, MMPs are likely to be essential for neuronal plasticity and angiogenesis (Rosenberg, 1995; Szklarczyk et al., 2002). In the present model, it remains possible that upregulation of MMPs in the dentate is related to remodeling and recovery. More detailed studies of these neuroplastic phenomena are outside the scope of the present study but require further investigation.

In summary, we used a combined pharmacologic and gene knock-out approach to show that MMP-9 contributes to delayed neuronal death in the hippocampus after transient global cerebral ischemia. These extracellular proteolytic pathways are consistent with concepts of cell-matrix homeostasis and may also be critical to hippocampal remodeling during recovery. Additional studies to delineate the relationship between dysregulated MMPs in the hippocampus with neurobehavioral outcomes are warranted.

\section{References}

Asahi M, Sumii T, Fini ME, Itohara S, Lo EH (2001a) Matrix metalloproteinase 2 gene knockout has no effect on acute brain injury after focal ischemia. NeuroReport 17:3003-3007.

Asahi M, Wang X, Mori T, Sumii T, Jung JC, Moskowitz MA, Fini ME, Lo EH (2001b) Effects of matrix metalloproteinase-9 gene knock-out on the proteolysis of blood-brain barrier and white matter components after cerebral ischemia. J Neurosci 21:7724-7732.

Bondy SC (1995) The relation of oxidative stress and hyperexcitation to neurological disease. Proc Soc Exp Biol Med 208:337-345.

Calderone A, Jover T, Noh KM, Tanaka H, Yokota H, Lin Y, Grooms SY, Regis R, Bennett VL, Zukin RS (2003) Ischemic insults depress the gene silencer REST in neurons destined to die. J Neurosci 23:2112-2121.

Chan PH (2001) Reactive oxygen radicals in signaling and damage in the ischemic brain. J Cereb Blood Flow Metab 21:2-14.

Chan PH, Kawase M, Murakami K, Chen SF, Li Y, Calaqui B, Reola L, Carlson E, Epstein CJ (1998) Overexpression of SOD1 in transgenic rats protects vulnerable neurons against ischemic damage after global cerebral ischemia reperfusion. J Neurosci 18:8292-8299.

Chen J, Zhu RL, Nakayama M, Kawaguchi K, Jin K, Stetler RA, Simon RP, Graham SH (1996) Expression of the apoptosis-effector gene, Bax, is up-regulated in vulnerable hippocampal CA1 neurons following global ischemia. J Neurochem 67:64-71.

Chen J, Nagayama T, Jin K, Stetler RA, Zhu RL, Graham SH, Simon RP (1998) Induction of caspase-3-like protease may mediate delayed neuronal death in the hippocampus after transient cerebral ischemia. J Neurosci 18:4914-4928.

Chen ZL, Strickland S (1997) Neuronal death in the hippocampus is promoted by plasmin-catalyzed degradation of laminin. Cell 91:917-925.

Choi DW (1996) Ischemia-induced neuronal apoptosis. Curr Opin Neurobiol 6:667-672.

Endo A, Nagai N, Urano T, Takada Y, Hashimoto K, Takada A (1999) Proteolysis of neuronal cell adhesion molecule by the tissue plasminogen activator-plasmin system after kainate injection in the mouse hippocampus. Neurosci Res 33:1-8.
Endoh M, Maiese K, Wagner JA (1994) Expression of the neural form of nitric oxide synthase by CA1 hippocampal neurons and other central nervous system neurons. Neuroscience 63:679-689.

Frisch SM, Francis H (1994) Disruption of epithelial cell-matrix interactions induces apoptosis. J Cell Biol 124:619-629.

Gary DS, Mattson MP (2001) Integrin signaling via the PI3-kinase-Akt pathway increases neuronal resistance to glutamate-induced apoptosis. J Neurochem 76:1485-1496.

Gary DS, Milhavet O, Camandola S, Mattson MP (2003) Essential role for integrin linked kinase in Akt-mediated integrin survival signaling in hippocampal neurons. J Neurochem 84:878-890.

Graham SH, Chen J (2001) Programmed cell death in cerebral ischemia. J Cereb Blood Flow Metab 21:99-109.

Gu Z, Kaul M, Yan B, Kridel SJ, Cul J, Strongin A, Smith JW, Liddington RC, Lipton SA (2002) S-nitrosylation of matrix metalloproteinases: signaling pathway to neuronal cell death. Science 297:1186-1190.

Kawase M, Murakami K, Fujimura M, Morita-Fujimura Y, Gasche Y, Knodo T, Scott RW, Chan PH (1999) Exacerbation of delayed cell injury after transient global ischemia in mutant mice with CuZn superoxide dismutase deficiency. Stroke 30:1962-1968.

Kesslak JP, Gage FH (1986) Recovery of spatial alternation deficits following selective hippocampal destruction with kainic acid. Behav Neurosci 100:280-283.

Lipton P (1999) Ischemic cell death in brain neurons. Physiol Rev 79:1431-1568.

Lo EH, Wang X, Cuzner ML (2002) Extracellular proteolysis in brain injury and inflammation: role for plasminogen activations and matrix metalloproteinases. J Neurosci Res 69:1-9.

Lo EH, Dalkara T, Moskowitz MA (2003) Mechanisms, challenges and opportunities in stroke. Nat Rev Neurosci 4:399-415.

Martin LJ, Al-Abdulla NA, Brambrink AM, Kirsch JR, Sieber FE, PorteraCailliau (1998) Neurodegeneration in excitotoxicity, global cerebral ischemia, and target deprivation: a perspective on the contributions of apoptosis and necrosis. Brain Res Bull 46:281-309.

Mun-Bryce S, Rosenberg GA (1998) Gelatinase B modulates selective opening of the blood-brain barrier during inflammation. Am J Physiol 274:R1203-1211.

Mun-Bryce S, Lukes A, Wallace J, Lukes-Marx M, Rosenberg GA (2002) Stromelysin- 1 and gelatinase A are upregulated before TNF-alpha in LPSstimulated neuroinflammation. Brain Res 933:42-49.

Murakami K, Kondo T, Epstein CJ, Chan PH (1997) Overexpression of CuZn-superoxide dismutase reduces hippocampal injury after global ischemia in transgenic mice. Stroke 28:1797-1804.

Nakatomi H, Kuriu T, Okabe S, Yamamoto S, Hatano O, Kawahara N, Tamura A, Kirino T, Nakafuku M (2002) Regeneration of hippocampal pyramidal neurons after ischemic brain injury by recruitment of endogenous neural progenitors. Cell 110:429-4241.

Oh LY, Larsen PH, Krekoski CA, Edwards DR, Donovan F, Werb Z, Yong VW (1999) Matrix metalloproteinase-9/gelatinase B is required for process outgrowth by oligodendrocytes. J Neurosci 19:8464-8475.

Paez Pereda M, Ledda MF, Goldberg V, Chervin A, Carrizo G, Molina H, Muller A, Renner U, Podhajcer O, Arzt E, Stalla GK (2000) High levels of matrix metalloproteinases regulate proliferation and hormone secretion in pituitary cells. J Clin Endocrinol Metab 85:263-269.

Pagenstecher A, Stalder AK, Kincaid CL, Shapiro SD, Campbell IL (1998) Differential expression of matrix metalloproteinase and tissue inhibitor of matrix metalloproteinase genes in the mouse central nervous system in normal and inflammatory states. Am J Pathol 152:729-741.

Pellegrini-Giampietro DE, Suzanne Zukin R, Bennett MVL, Cho S, Pulsinelli WA (1992) Switch in glutamate receptor subunit gene expression in CA1 subfield of hippocampus following global ischemia in rats. Proc Natl Acad Sci USA 89:10499-10503.

Power C, Henry S, Del Bigio MR, Larsen PH, Corbett D, Imai Y, Yong VW, Peeling J (2003) Intracerebral hemorrhage induces macrophage activation and matrix metalloproteinases. Ann Neurol 53:731-742.

Pulsinelli WA (1985) Selective neuronal vulnerability: morphological and molecular characteristics. Prog Brain Res 63:29-37.

Rivera S, Ogier C, Jourquin J, Timsit S, Szklarczyk AW, Miller K, Gearing AJH, Kaczmarek L, Khrestchatisky (2002) Gelatinase B and TIMP-1 are regulated in a cell- and time-dependent manner in association with neuronal death and glial reactivity after global forebrain ischemia. Eur J Neurosci 15:19-22. 
Romanic AM, White RF, Arleth AJ, Ohlstein EH, Barone FC (1998) Matrix metalloproteinase expression increases after cerebral focal ischemia in rats: inhibition of matrix metalloproteinase- 9 reduces infarct size. Stroke 29:1020-1030.

Ramirez JJ (2001) The role of axonal sprouting in functional reorganization after CNS injury: lessons from the hippocampal formation. Restor Neurol Neurosci 19:237-262.

Rosenberg GA (1995) Matrix metalloproteinases in brain injury. J Neurotrauma 12:833-842.

Rosenberg GA (2002) Matrix metalloproteinases in neuroinflammation. Glia 39:279-291

Rosenberg GA, Cunningham LA, Wallace J, Alexander S, Estrada EY, Grossetete M, Razhagi A, Miller K, Gearing A (2001) Immunohistochemistry of matrix metalloproteinases in reperfusion injury to rat brain: activation of MMP-9 linked to stromelysin-1 and microglia in cell cultures. Brain Res 893:104-112.

Sappino AP, Madani R, Huarte J, Belin D, Kiss JZ, Wohlwend A, Vassalli JD (1993) Extracellular proteolysis in the adult murine brain. J Clin Invest 92:679-685.

Schulz JB, Wree A, Schleicher A, Zilles K (1992) Plasticity in the rat hippocampal formation following ibotenic acid lesion of the septal region: a quantitative $\left[{ }^{14} \mathrm{C}\right.$ ]deoxyglucose and acetylcholinesterase study. J Cereb Blood Flow Metab 12:1007-1021.

Szklarczyk A, Lapinska J, Rylski M, McKay RDG, Kaczmarek L (2002) Matrix metalloproteinase- 9 undergoes expression and activation during dendritic remodeling in adult hippocampus. J Neurosci 22:920-930.

Tsirka SE, Rogove AD, Strickland S (1996) Neuronal cell death and tPA. Nature 384:123-124.

Tsirka SE, Rogove AD, Bugge TH, Degen JL, Strickland S (1997) An extracellular proteolytic cascade promotes neuronal degeneration in the mouse hippocampus. J Neurosci 17:543-552.

Vu TH, Shipley JM, Bergers G, Berger JE, Helms JA, Hanahan D, Shapiro SD, Senior RM, Werb Z (1998) MMP-9/gelatinas B is a key regulator of growth plate angiogenesis and apoptosis of hypertrophic chondrocytes. Cell 93:411-422.

Wang X, Barone FC, White RF, Feuerstein GZ (1998) Subtractive cloning identifies tissue inhibitor of matrix metalloproteinase-1 (TIMP-1) increased gene expression following focal stroke. Stroke 29:516-520.

Wang X, Jung JC, Asahi M, Chwang W, Russo L, Moskowitz MA, Dixon CE, Fini E, Lo EH (2000) Effects of matrix metalloproteinase-9 gene knockout on morphological and motor outcomes after traumatic brain injury. J Neurosci 20:7037-7042.

Wang X, Lee SR, Arai K, Lee SR, Tsuji K, Rebeck GW, Lo EH (2003) Lipoprotein receptor mediated induction of matrix metalloproteinase by tissue plasminogen activator. Nat Med 9:1313-1319.

Wetzel M, Rosenberg GA, Cunningham LA (2003) Tissue inhibitor of metalloproteinases-3 and matrix metalloproteinase- 3 regulate neuronal sensitivity to doxorubicin-induced apoptosis. Eur J Neurosci 18:1050-1060.

Wieloch T, Lindvall O, Blomqvist P, Gage FH (1985) Evidence for amelioration of ischemic neuronal damage in the hippocampal formation by lesions of the perforant path. Neurol Res 7:24-26.

Wilde GJC, Pringle AK, Wright P, Iannotti F (1997) Differential vulnerability of the CA1 and CA3 subfields of the hippocampus to superoxide and hydroxyl radicals in vitro. J Neurochem 69:883-886.

Yong VW, Krekoski CA, Forsyth PA, Bell R, Edwards DR (1998) Matrix metalloproteinases and disease of the CNS. Trends Neurosci 21:75-80.

Yong VW, Power C, Forsyth P, Edward DR (2001) Metalloproteinases in biology and pathology of the nervous system. Nat Rev Neurosci 2:502-511.

Yong VW, Larsen P, Weaver A, Wells J (2003) Multiple facets of matrix metalloproteinase in the nervous system. J Neurochem 85 [Suppl 1]:91.

Zalewska T, Ziemka-Nalecz M, Sarnowska A, Domanska-Janik K (2002) Involvement of MMPs in delayed neuronal death after global ischemia. Acta Neurobiol Exp (Warsz) 62:53-61.

Zalewska T, Ziemka-Nalecz M, Sarnowska A, Domanska-Janik K (2003) Transient forebrain ischemia modulates signal transduction from extracellular matrix in gerbil hippocampus. Brain Res 977:62-69. 